\title{
Uso da matéria orgânica como mitigadora de solo multicontaminado e do girassol como fitoextratora
}

\author{
$\overline{\text { Mariana B. Gabos', Giseli Casagrande', Cleide A. Abreu1 \& Jorge Paz-Ferreiro }{ }^{2}}$
}

\section{RESUMO}

Objetivou-se, com este trabalho, avaliar a torta de filtro e a turfa como fontes de matéria orgânica (MO) para mitigar solo contaminado com boro, sob o cultivo do girassol. O delineamento experimental adotado foi inteiramente casualizado e os tratamentos foram distribuídos em esquema fatorial 2 (materiais orgânicos) x 4 (doses de cada fonte de matéria orgânica), com três repetições. As doses de cada material orgânico adicionado se fundamentaram nos teores de C, sendo equivalentes a 0, 20, 40 e 80 t ha ${ }^{1}$. Em cada parcela experimental foram utilizados vasos contendo 5,0 kg de solo contaminado cultivados com três plantas de girassol, durante 65 dias. As plantas não apresentaram sintomas de toxicidade por B, Cu e Zn, embora seus teores na parte aérea tenham sido elevados. O tipo de matéria orgânica influenciou significativamente a produção de massa seca do caule, flor e raiz, sendo que a adição de torta de filtro promoveu maior produção. O tempo de remoção necessário para retirar $50 \%$ do teor total de B do solo seria de 11,1 anos sem uso de $\mathrm{MO}, 15$ anos com uso da torta de filtro e 25 anos com uso da turfa. O girassol tem potencial para ser cultivado na área contaminada com resíduo metálico e a aplicação de torta de filtro ou de turfa não foi eficiente como mitigadora de metais pesados e de B.

Palavras-chave: boro, torta de filtro, turfa, metais pesados, fitorremediação

\section{Use of organic matter to mitigate multicontaminated soil and sunflower plants as phytoextractor}

\begin{abstract}
The objective of this study was to evaluate the filter cake and peat as sources of organic matter (OM) in order to mitigate contaminated soil with boron, under the sunflower cultivation. The experimental design adopted was completely randomized in a factorial scheme distributed in 2 (organic matter types) $\mathrm{x} 4$ (organic matter dose of each type), with three replications. The doses of each organic material added were based on the content of $\mathrm{C}$, being equivalent to $0,20,40$ and $80 \mathrm{t} \mathrm{ha}^{-1}$. In each experimental plot, pots containing $5.0 \mathrm{~kg}$ of contaminated soil was cultivated with three plants of sunflower during 65 days. The plants showed no symptoms of toxicity of $\mathrm{B}, \mathrm{Cu}$ and $\mathrm{Zn}$, although high levels were observed in the aerial part. The type of organic matter significantly influenced the dry mass of stem, flower and root, though the addition of filter cake promoted higher production. The time required to remove $50 \%$ of the total content of B in soil was 11.1 years without the use of OM, 15 years with the use of filter cake and 25 years with the use of peat. The sunflower has the potential to be grown in the contaminated area and the application of filter cake or peat was not as efficient in mitigation of heavy metals and B.
\end{abstract}

Key words: boron, filter cake, peat, heavy metals, phytoremediation 


\section{INTRODUÇÃO}

Comumente, o aumento de áreas contaminadas por metais pesados é atribuído ao elevado nível de industrialização. Parte deste incremento é resultado da intensificação da fiscalização de órgãos ambientais, como a CETESB, aplicando as leis com maior rigor, a fim de minimizar os impactos ao ambiente. Segundo (CETESB, 2010a), no Estado de São Paulo foram detectadas, em novembro de 2008, 2.514 áreas contaminadas, em que a região de Piracicaba ocupa o segundo lugar, totalizando 380 áreas, seguida do Alto Tietê, com 1260. Dentre os grupos contaminantes o de metais pesados se situa em quarto lugar e foi responsável pela contaminação de 300 áreas.

Como meio promissor para reciclagem de vários resíduos com a finalidade de melhorar seus atributos físicos e fornecer nutrientes às plantas, muitas vezes o solo recebe disposição inadequada de resíduos industriais (Matos et al., 2010; Barros et al., 2011; Sobral et al., 2011), acarretando problemas ambientais de difícil solução (Gabos et al., 2009). Um exemplo ocorreu no Sítio São Luiz, no município de Piracicaba, quando foi adicionado ao solo,inadequadamente, resíduo de sucata de composição metálica com a finalidade de repor micronutrientes de interesse agronômico, causando contaminação do solo por vários elementos e risco de contaminação das águas subterrâneas (Jorge et al., 2010).

A acumulação, no solo, de metais pesados e outros elementos, como o boro, é uma via significativa de contaminação da cadeia trófica, necessitando de controle, visto que sua descontaminação tem assumido importância crescente, fator essencial para a sustentabilidade dos recursos naturais e da vida, no nosso planeta (Santos \& Rodella, 2007). Dentre as várias formas de remover contaminantes dos solos, além das técnicas físico-químicas que possuem custo altíssimo, podese citar a fitorremediação, que emprega plantas para degradar, extrair (acumulação ou volatilização) e estabilizar (imobilização) os contaminantes (Gratão et al., 2005). Esta técnica apresenta a vantagem de poder ser utilizada em grandes áreas a um baixo custo e, ainda, de melhorar a paisagem e a estética local; tratase de uma técnica conservacionista, que valoriza as áreas adjacentes e sem custo energético (Gratão et al., 2005; Gabos et al., 2009; Assis et al., 2010).

O sucesso da fitoextração depende de alguns fatores, destacando-se o grau de contaminação do metal no solo, a biodisponibilidade do metal, a capacidade das plantas em acumularem o metal na parte aérea e sua elevada produção de biomassa (Gratão et al., 2005; Kolbas et al., 2011).

Estudos comprovaram a eficiência de muitas espécies fitoextratoras de metais pesados no solo havendo aproximadamente 400 espécies hiperacumuladoras de diversos metais pesados (Gratão et al., 2005; Cassina et al., 2011). Hoje, há tendência do uso de plantas energéticas como fitoextratoras de metais pesados convertendo a biomassa em biodiesel (Ruttens et al., 2011). Assim, esta tecnologia se torna mais ecologicamente correta, despoluindo áreas e contribuindo para o uso de energia menos poluente ao ambiente. Algumas dessas espécies, como mamona (Romeiro et al., 2006), girassol (Zeittouni et al., 2007), milho (Pereira et al., 2007), nabo forrageiro (Jorge et al., 2010), mostarda (Santos \& Rodella, 2007) já foram avaliadas como fitoextratoras de vários metais e de B em solos contaminados, principalmente no Estado de São Paulo, com resultados promissores.

Muitas vezes, o grau de contaminação do solo é altíssimo fazendo com que a técnica de fitoextração não tenha sucesso em razão da dificuldade de estabelecimento da vegetação, casos em que é recomendável, primeiramente, estabilizar o contaminante, reduzindo-o a um nível mais tolerável às plantas.

Dentre os vários mitigadores de metais se destacam a calagem e os materiais orgânicos (Ribeiro Filho et al., 2001; Santos \& Rodella, 2007; Correa et al., 2008). Com a elevação do $\mathrm{pH}$ a maioria dos metais pesados tem sua disponibilidade diminuída e, consequentemente, menor absorção pelas plantas e menor risco de lixiviação (Corrêa et al., 2008). Outro mitigador importante é a matéria orgânica, que pode formar complexos insolúveis com metais pesados e outros elementos, tornandoos menos disponíveis às plantas e, assim, possibilitando o cultivo de plantas em áreas cuja contaminação esteja muito elevada (Ribeiro Filho et al., 2001; Santos et al., 2011).

O objetivo deste experimento foi avaliar o desempenho do girassol (Helianthus annuus Mill), planta bioenergética, como remediadora de áreas contaminadas com metais pesados e boro, e o efeito da aplicação de compostos orgânicos na disponibilidade de metais e de boro para o girassol.

\section{Material e MÉTOdos}

O experimento foi conduzido em casa de vegetação nas dependências da sede do Instituto Agronômico, Campinas, com coordenadas geográficas aproximadas de latitude $22^{\circ} 53^{\prime}$ 34.11" S e longitude 47 03' 43.94" O. O clima é mesotérmico (com verões quentes e estação seca de inverno), ou seja, o mês mais frio apresenta média mensal inferior à $18^{\circ} \mathrm{C} \mathrm{e}$, no verão, o mês mais quente tem média superior a $22^{\circ} \mathrm{C}$; no mês mais seco recebe menos de $60 \mathrm{~mm}$ de chuva. O local de coleta deste solo, com área de aproximadamente 3 ha, foi contaminado em razão de descarte de resíduo de sucata metálica rica em B. A área foi interditada pelo órgão ambiental e, logo após a interdição, foi feita a aplicação de 10 t ha ${ }^{-1}$ de calcário dolomítico ao solo, elevando o $\mathrm{pH}$ para 7,5. O solo foi classificado como Neossolo Litólico Chernossólico fragmentário, textura média e imperfeitamente drenado.

A amostra de solo foi coletada na camada de $0-20 \mathrm{~cm}$ de profundidade, secada ao ar e peneirada em peneira de malha de 2,0 mm. Os teores totais de B e metais pesados extraídos pelo método 3051 U.S.EPA, SW-846 (USEPA, 2007) foram, em $\mathrm{mg} \mathrm{kg}^{-1}$, de: B-62, Cu-334, Fe-38.650, Mn-578, Zn-2.997, Cd-4,5, $\mathrm{Cr}-89, \mathrm{Ni}-53,0$ e $\mathrm{Pb}-358$. Análise de rotina, com a finalidade de determinar os teores disponíveis de alguns elementos, foi feita conforme descrito em van Raij et al. (2001). Os valores obtidos foram: $\mathrm{pH}_{\mathrm{CaCl} 2}=7,5 ; \mathrm{MO}=30,5 \mathrm{~g} \mathrm{dm}^{-3} ; \mathrm{B}_{\text {ápua }}=8,5 \mathrm{mg} \mathrm{dm}^{-3}$, $\mathrm{P}_{\text {resina }}=43,3 \mathrm{mg} \mathrm{dm}^{-3} ; \mathrm{K}_{\text {resina }}=2,6 \mathrm{mmol}_{\mathrm{c}} \mathrm{dm}^{-3} ; \mathrm{Ca}_{\text {resina }}=294$ $\mathrm{mmol}_{\mathrm{c}} \mathrm{dm}^{-3} ; \mathrm{Mg}_{\text {resina }}=59 \mathrm{mmol}_{\mathrm{c}} \mathrm{dm}^{-3} ; \mathrm{CTC}=364 \mathrm{mmol}_{\mathrm{c}} \mathrm{dm}^{-3}$; $\mathrm{H}+\stackrel{\mathrm{c}}{\mathrm{A}}=9,0 \mathrm{mmol} \mathrm{dm}^{-3} ; \mathrm{V}=98 \%$. Os metais pesados foram extraídos usando o método DTPA pH 7,3 (Raij et al. 2001) cujos resultados em $\mathrm{mg} \mathrm{dm}^{-3}$, foram de: $\mathrm{Cu}=61,6 ; \mathrm{Fe}=15,0$; $\mathrm{Mn}=12,0 ; \mathrm{Zn}=452 ; \mathrm{Cd}=0,72 ; \mathrm{Cr}=<0,01 ; \mathrm{Ni}=2,0 \mathrm{e} \mathrm{Pb}=29$. 
Tabela 1. Valores de $\mathrm{pH}$, condutividade elétrica, teor de $\mathrm{C}$ orgânico e alguns nutrientes disponíveis no material orgânico adicionado ao solo

\begin{tabular}{|c|c|c|c|c|c|c|c|c|c|c|c|c|}
\hline \multirow{2}{*}{ Fonte $\mathrm{C}$ org. } & \multirow{2}{*}{$\mathrm{pH}$} & \multirow{2}{*}{$\begin{array}{c}\text { CE } \\
\mathrm{dS} \mathbf{m}^{-1}\end{array}$} & \multirow{2}{*}{$\begin{array}{l}\text { C org. } \\
\mathbf{g ~ k g}^{-1}\end{array}$} & $\mathrm{~N}-\mathrm{NO}_{3}{ }^{-}$ & $\mathrm{N}-\mathrm{NH}_{4}^{+}$ & $\mathbf{P}$ & $\mathrm{K}$ & B & $\mathrm{Cu}$ & $\mathrm{Fe}$ & $M n$ & $\mathrm{Zn}$ \\
\hline & & & & \multicolumn{9}{|c|}{$\mathrm{mg} \mathrm{kg}^{-1}$} \\
\hline $\begin{array}{c}\text { Torta de filtro } \\
\text { Turfa }\end{array}$ & $\begin{array}{l}7,5 \\
5,5\end{array}$ & $\begin{array}{l}0,9 \\
0,2\end{array}$ & $\begin{array}{l}264 \\
163\end{array}$ & $\begin{array}{l}3,5 \\
8,6\end{array}$ & $\begin{array}{r}61 \\
2\end{array}$ & $\begin{array}{r}10,1 \\
0,1\end{array}$ & $\begin{array}{r}37,0 \\
2,9\end{array}$ & $\begin{array}{r}<0,01 \\
0,02\end{array}$ & $\begin{array}{l}0,05 \\
0,01\end{array}$ & $\begin{array}{l}0,50 \\
0,02\end{array}$ & $\begin{array}{l}0,50 \\
0,02\end{array}$ & $\begin{array}{l}0,04 \\
0,01\end{array}$ \\
\hline
\end{tabular}

* Método da extração 1:1,5 descrito por Abreu et al. (2007)

Como fontes de matéria orgânica foram utilizadas a torta de filtro e a turfa (Tabela 1). A torta de filtro é um resíduo proveniente do tratamento do caldo de cana-de-açúcar na indústria açucareira e a turfa é um material orgânico natural, estabilizado e reconhecido por sua alta capacidade de troca iônica.

O cálculo das doses foi baseado no teor de $\mathrm{C}$ orgânico de cada material, equivalente a $0,20,40 \mathrm{e} 80 \mathrm{tha}^{-1}$ de C. Esses valores foram em $\mathrm{g} \mathrm{kg}^{-1}$, iguais a: $0 ; 37,9 ; 75,8$ e 151,6 para a torta de filtro e de $0 ; 61,3 ; 122,6$ e 245,2 para a turfa. Após a adição dos materiais orgânicos ao solo foram feitas a mistura e a homogeneização, mantendo-se a umidade do solo em $60 \%$ da capacidade máxima de retenção. $\mathrm{O}$ solo foi incubado durante 35 dias; aos 20 dias de incubação promoveu-se a adição de $\mathrm{P}$ em dose equivalente a $200 \mathrm{mg} \mathrm{kg}^{-1}$, na forma de superfosfato triplo, seguindo-se de homogeneização e incubação, por mais 15 dias.

O delineamento experimental adotado foi o inteiramente casualizado e os tratamentos foram distribuídos em esquema fatorial $2 \times 4$, sendo o primeiro fator constituído de 2 fontes de matéria orgânica e o segundo por 4 doses de cada fonte, com três repetições, totalizando 24 parcelas experimentais. Cada parcela experimental foi constituída de vaso contendo $5,0 \mathrm{~kg}$ de terra e três plantas de girassol (Helianthus annuus Mill). Durante a condução do ensaio fez-se o suprimento de água destilada mantendo-se $60 \%$ da capacidade máxima de retenção de água no solo, por meio de pesagens diárias dos vasos. Adubação nitrogenada foi feita quinzenalmente, adicionandose $30 \mathrm{mg} \mathrm{kg}^{-1}$ de $\mathrm{N}$ por aplicação, na forma de solução contendo nitrato de amônio.

O corte do girassol foi realizado aos 65 dias da semeadura, após $80 \%$ do florescimento das plantas, separando-se flor, caule + folhas (parte aérea) e raízes. O material vegetal (parte aérea + flor) foi lavado em água corrente, seguido de uma solução a $1 \% \mathrm{de} \mathrm{HCl}$, água destilada e conduzido para secagem em estufa a $70^{\circ} \mathrm{C}$ com circulação de ar, até atingir peso constante; em seguida, o material vegetal foi pesado e triturado em moinho tipo Wiley. As raízes foram separadas da terra por peneiramento, retirando-se o excesso de terra com auxílio de uma pequena escova; depois, foram lavadas em água corrente e imersas, por 90 minutos, em solução $0,02 \mathrm{mmol} \mathrm{L}^{-1}$ de EDTA dissódico e em seguida lavadas em água destilada, secadas e moídas do mesmo modo que na parte aérea. Todo o material vegetal foi pesado até atingir peso constante; logo após, foi submetido à digestão com $\mathrm{HNO}_{3} / \mathrm{H}_{2} \mathrm{O}_{2}$ em forno de micro-ondas (Abreu, 1997), para posterior determinação dos vários elementos, através do espectrômetro de emissão por plasma (ICP-OES).

Nas amostras de solo, coletadas após o período de incubação e antes da semeadura, foram determinados os teores totais dos elementos, de acordo com o método 3051 U.S.EPA,
SW-846 (USEPA, 2007), empregando-se ácido nítrico e aquecimento em forno de micro-ondas. A determinação dos teores disponíveis de metais pesados $(\mathrm{Cu}, \mathrm{Fe}, \mathrm{Mn}, \mathrm{Zn}, \mathrm{Cd}, \mathrm{Cr}$, $\mathrm{Ni} \mathrm{e} \mathrm{Pb)} \mathrm{foi} \mathrm{feita} \mathrm{usando-se} \mathrm{o} \mathrm{extrator} \mathrm{DTPA} \mathrm{a} \mathrm{pH} \mathrm{7,3} \mathrm{(Raij} \mathrm{et} \mathrm{al.}$ 2001). Nos extratos obtidos foram feitas quantificações dos vários elementos, com o espectrômetro de emissão por plasma (ICP-OES). A extração de boro disponível foi realizada pelo método da água quente usando-se forno de micro-ondas caseiro como fonte de aquecimento e a azometina-H na determinação (Raij et al., 2001).

Os resultados foram submetidos à análise de variância (ANOVA) e, no caso do teste F significativo (ANOVA), aplicado o teste de Tukey a $5 \%$ para comparação de médias entre os materiais orgânicos e análise de regressão para doses (modelo linear ou quadrático). No caso de interação significativa entre os fatores estudados, fez-se o desdobramento.

Fez-se o cálculo da transferência e translocação dos elementos na planta conforme descrito em Gabos et al. (2009) e Jorge et al (2010). A transferência (F) foi obtida através da fórmula $\mathrm{F}=\mathrm{CPT} / \mathrm{CT}$, em que: $\mathrm{CPT}=$ concentração dos elementos na planta, $\mathrm{mg} \mathrm{kg}^{-1} \mathrm{e} \mathrm{CT}=$ concentração total dos elementos no solo, $\mathrm{mg} \mathrm{kg}^{-1}$. A translocação dos elementos da raiz para a parte aérea (IT) foi calculada pela equação: IT \% $=(\mathrm{QPA} / \mathrm{QAP})$ x 100, em que: $\mathrm{QPA}=$ quantidade acumulada dos elementos na parte aérea, $\mathrm{mg}$ por vaso; $\mathrm{QAP}=$ quantidade acumulada dos elementos na planta, mg por vaso.

O tempo de remoção, em anos, necessário para reduzir em $50 \%$ o teor dos elementos, foi estimado pela fórmula: $\mathrm{T}=(\mathrm{R} /$ $\mathrm{E} \%$ ) / NC, sendo R a porcentagem do elemento a ser removido do solo, E\% a eficiência de remoção e NC é o número de ciclos da cultura. O percentual de remoção (R) foi arbitrado em 50\%, embora não haja valor de referência para esses elementos, definido pela CETESB. Nesses cálculos se considerou apenas um ciclo de cultivo por ano.

\section{RESULTADOS E DISCUSSÃO}

Teores totais e disponíveis dos elementos no solo contaminado Com base nos valores orientadores sugeridos pela CETESB (CETESB, 2010b), os teores de $\mathrm{Cr}-89 \mathrm{mg} \mathrm{kg}^{-1} \mathrm{e} \mathrm{Ni}-53 \mathrm{mg} \mathrm{kg}^{-1}$ da área contaminada estavam entre os valores de prevenção $\left(\mathrm{Cr}-75 \mathrm{mg} \mathrm{kg}^{-1} \mathrm{e} \mathrm{Ni}-30 \mathrm{mg} \mathrm{kg}^{-1}\right)$ e de intervenção agrícola $(\mathrm{Cr}$ $150 \mathrm{mg} \mathrm{kg}^{-1} \mathrm{e} \mathrm{Ni}-70 \mathrm{mg} \mathrm{kg}^{-1}$ ). Os teores de Cd $-4,5 \mathrm{mg} \mathrm{kg}^{-1} \mathrm{e}$ de $\mathrm{Cu} 334 \mathrm{mg} \mathrm{kg}^{-1}$ se mantiveram entre os valores de intervenção agrícola $\left(\mathrm{Cd}-3 \mathrm{mg} \mathrm{kg}^{-1}\right.$ e $\left.\mathrm{Cu}-200 \mathrm{mg} \mathrm{kg}^{-1}\right)$ e residencial $\left(\mathrm{Cd}-8 \mathrm{mg} \mathrm{kg}^{-1} \mathrm{e} \mathrm{Cu}-400 \mathrm{mg} \mathrm{kg}^{-1}\right)$. O Pb - 358 $\mathrm{mg} \mathrm{kg}^{-1}$ estava bem próximo ao de intervenção residencial, 300 mg kg-1; já o Zn - $2997 \mathrm{mg} \mathrm{kg}^{-1}$, o mais preocupante, ultrapassou o limite de intervenção industrial, em cerca de 50\%. Quanto ao 
B, a CETESB não tem legislação para níveis de qualidade do solo. Em relação ao valor máximo permitido de B em solo austríaco, $100 \mathrm{mg} \mathrm{kg}^{-1}$ (Kabata-Pendias, 2001), pode-se considerar que o teor deste elemento na amostra de solo de Piracicaba $\left(62 \mathrm{mg} \mathrm{kg}^{-1}\right)$ estava elevado.

A adição de matéria orgânica ao solo influenciou apenas o teor total de fósforo, que foi de $427 \mathrm{mg} \mathrm{kg}^{-1}$ pela aplicação de torta de filtro e de $322 \mathrm{mg} \mathrm{kg}^{-1}$ quando da aplicação de turfa. $\mathrm{O}$ teor de $\mathrm{P}$ contido na torta de filtro $\left(0,38 \mathrm{mg} \mathrm{kg}^{-1}\right)$ foi aproximadamente 8 vezes maior que o adicionado em massa com base no teor de C pela turfa $\left(0,05 \mathrm{mg} \mathrm{kg}^{-1}\right)$ (Tabela 1$)$. Segundo Santos et al. (2011) a torta de filtro é um material considerado rico em N, P e Ca e, portanto, deve ter contribuído para o aumento de $\mathrm{P}$ no solo.
O maior teor de $\mathrm{P}$ total nos tratamentos que receberam adição de torta de filtro refletiu na sua maior disponibilidade para as plantas (Tabela 2 e Figura 1). Além do fósforo, o B teve sua disponibilidade influenciada pela aplicação da matéria orgânica, com aumento pelo uso da torta de filtro (Tabela 2). Com a aplicação desse material orgânico, o teor médio de $\mathrm{B}$ disponível aumentou $0,8 \mathrm{mg} \mathrm{dm}^{-3}$ representando um incremento de $10 \%$. Este aumento foi expressivo considerando-se a faixa de teor adequado de $\mathrm{B}$ em solos entre 1,2 a $3,0 \mathrm{mg} \mathrm{dm}^{-3}$ para a maioria das culturas (Abreu et al., 2005). O aumento nas disponibilidades de $\mathrm{P}$ e de $\mathrm{B}$ pelo uso de torta de filtro pode ser explicado com relação à sua composição (Tabela 1) e à sua qualidade. A torta de filtro, por apresentar a mais baixa relação C/N (Tabela 1) em comparação com a turfa, é mais facilmente

Tabela 2. Efeito da aplicação de doses de torta de filtro e turfa no solo nos valores de matéria orgânica, pH e teores disponíveis de fósforo, boro e metais pesados

\begin{tabular}{|c|c|c|c|c|c|c|c|c|c|c|c|c|c|}
\hline \multirow{2}{*}{$\begin{array}{l}\text { Fonte } \\
\text { C org. }\end{array}$} & \multirow{2}{*}{$\begin{array}{c}\text { Dose } \\
\text { C org. (t ha-1) }\end{array}$} & \multirow{2}{*}{$\begin{array}{c}M 0 \\
\left(\mathrm{~g} \mathrm{dm}^{-3}\right)\end{array}$} & \multirow{2}{*}{$\begin{array}{c}\mathrm{pH} \\
\mathrm{CaCl}_{2}\end{array}$} & \multirow{2}{*}{$\begin{array}{l}\text { P resina } \\
\left(\mathrm{mg} \mathrm{dm}^{-3}\right)\end{array}$} & \multirow{2}{*}{$\begin{array}{c}B \\
A Q\end{array}$} & $\mathrm{Cu}$ & $\mathrm{Fe}$ & Mn & $\mathrm{Zn}$ & Cd & $\mathrm{Cr}$ & $\mathrm{Ni}$ & $\mathrm{Pb}$ \\
\hline & & & & & & \multicolumn{8}{|c|}{ DTPA $\left(\mathrm{mg} \mathrm{dm}^{-3}\right)$} \\
\hline & 0 & 31,0 & 7,4 & 42 & 8,8 & 54 & 18 & 12 & 452 & 0,7 & 0,0 & 2,0 & 15 \\
\hline & 20 & 33,5 & 7,6 & 83 & 8,8 & 54 & 22 & 14 & 435 & 0,6 & 0,0 & 1,8 & 19 \\
\hline Torta de filtro & 40 & 37,0 & 7,5 & 125 & 8,5 & 53 & 27 & 12 & 411 & 0,6 & 0,0 & 1,8 & 29 \\
\hline & 80 & 42,0 & 7,6 & 176 & 8,6 & 68 & 17 & 13 & 451 & 0,7 & 0,0 & 2,0 & 17 \\
\hline \multirow{4}{*}{ Turfa } & 0 & 30,0 & 7,6 & 45 & 8,1 & 69 & 14 & 12 & 452 & 0,8 & 0,0 & 2,0 & 13 \\
\hline & 20 & 31,5 & 7,6 & 41 & 8,0 & 76 & 18 & 10 & 439 & 0,8 & 0,0 & 1,9 & 21 \\
\hline & 40 & 31,5 & 7,5 & 42 & 7,9 & 64 & 22 & 12 & 423 & 0,8 & 0,0 & 1,9 & 18 \\
\hline & 80 & 32,0 & 7,4 & 36 & 7,7 & 47 & 36 & 11 & 377 & 0,6 & 0,0 & 1,8 & 23 \\
\hline Tratamento & & * & ns & * & * & * & ns & ns & ns & ns & ns & ns & ns \\
\hline Dose & & * & ns & * & ns & ns & $\star$ & ns & $\star$ & ns & ns & ns & ns \\
\hline Interação & & * & ns & * & ns & * & * & ns & * & ns & ns & ns & ns \\
\hline
\end{tabular}

(ns) não significativo e $\left(^{*}\right)$ significativo; médias seguidas de letras diferentes na coluna diferem entre si a nível de 5\% pelo teste de Tukey, comparação entre tipos de material orgânico
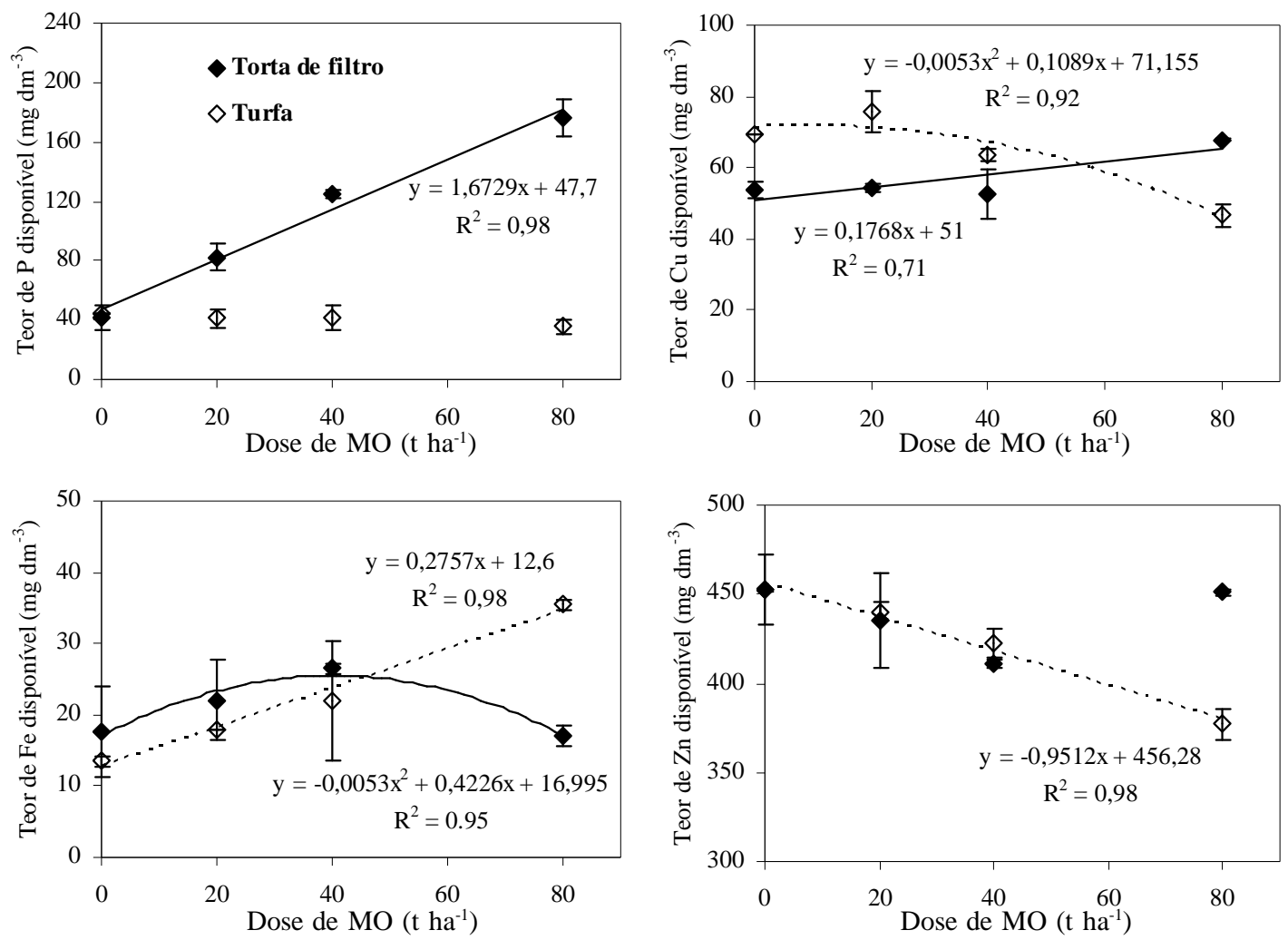

Figura 1. Desdobramento do efeito das doses de torta de filtro e turfa aplicadas ao solo, para as interações significativas $(p<0,05)$ referentes aos teores disponíveis de $\mathrm{P}, \mathrm{Cu}, \mathrm{Fe}$ e $\mathrm{Zn}$ em solos 
degradada, disponibilizando os nutrientes complexados no material orgânico. Comumente, a solubilização de nutrientes em materiais orgânicos é relacionada com a presença de ácidos fúlvicos em maiores proporções que ácidos húmicos sendo que, para biossólidos frescos, por exemplo, com menor grau de humificação, há mais ácidos fúlvicos que húmicos (Kumpiene et al., 2008). Por outro lado, na turfa há predominância de ácidos húmicos em relação aos ácidos fúlvicos, em função do maior tempo necessário para sua formação e da maior estabilidade orgânica, conforme observado nos trabalhos de Franchi et al. (2003).

Ocorreu efeito das doses nos teores disponíveis de P, Fe, $\mathrm{Cu}$ e $\mathrm{Zn}$ (Figura 1). Com o aumento da dose da torta de filtro houve aumento linear na disponibilidade de $\mathrm{PeCu}$ e diminuição na disponibilidade de Zn (Figura 1). No caso do Fe o ajuste foi linear crescente para a turfa e quadrático para torta de filtro. Chama-se a atenção para o fato de que os teores de $\mathrm{Cu}$ e $\mathrm{Zn}$ no solo foram mais elevados que os considerados normais para o desenvolvimento das plantas. Abreu et al. (2005) citam que valores disponíveis no solo maiores que $15 \mathrm{mg} \mathrm{kg}^{-1}$ de $\mathrm{Cu}$ (DTPA pH 7,3) e $130 \mathrm{mg} \mathrm{kg}^{-1}$ de Zn (DTPA pH 7,3) geralmente causam toxicidade às plantas.

\section{Produção de massa seca pelo girassol e concentração de nutrientes}

A produção de massa seca da raiz, parte aérea (caule + folha) e flor do girassol, foi influenciada pelos tratamentos (Figura 2). O uso da torta de filtro proporcionou maior produção de massa seca da raiz, parte aérea e flor (Figura 2) evento que pode ser justificado, sobretudo pelo elevado teor de fósforo nesse material orgânico (Tabela 1). Com base na análise do solo após a incubação dos materiais orgânicos e antes do plantio do girassol, chama-se a atenção para o fato de que a adição de torta de filtro promoveu um aumento na disponibilidade de $\mathrm{P}_{\text {resina }}$ (Tabela 2). O efeito da maior disponibilidade de P no solo refletiu no teor deste elemento no caule $1,8 \mathrm{~g} \mathrm{~kg}^{-1}$ (torta de filtro) e $1,5 \mathrm{~g} \mathrm{~kg}^{-1}$ (turfa) e na flor $3,1 \mathrm{~g} \mathrm{~kg}^{-1}$ (torta de filtro) e 2,3 $\mathrm{g} \mathrm{kg}^{-1}$ (turfa).

O efeito da aplicação de doses crescentes de matéria orgânica na produção de massa seca da parte aérea e raiz foi significativo e quadrático quando do uso de torta de filtro (Figura 2). As maiores produções de massa seca da parte aérea e raiz foram obtidas pela aplicação de $40 \mathrm{t} \mathrm{ha}^{-1}$ de torta de filtro.

Sintomas visuais de toxicidade de boro ou metais pesados não foram observados durante a condução do ensaio embora as plantas de girassol não estivessem muito vigorosas. Chamase a atenção para as altas concentrações de B, $\mathrm{Cu}$ e $\mathrm{Zn}$ no caule das plantas de girassol sendo a média, respectivamente para torta de filtro e turfa, de: 385 e $374 \mathrm{mg} \mathrm{kg}^{-1}$ para B; 305 e 289 $\mathrm{mg} \mathrm{kg}^{-1}$ para Cu e 338 e $473 \mathrm{mg} \mathrm{kg}^{-1}$ para Zn. Raij et al. (1997) citam que a concentração máxima adequada em folhas de girassol é de 100, 100 e $80 \mathrm{mg} \mathrm{kg}^{-1}$, respectivamente para $\mathrm{B}, \mathrm{Cu}$ e Zn. Ruy et al. (1990) verificaram que concentrações de B acima de $100 \mathrm{mg} \mathrm{kg}^{-1}$ em folhas de girassol foram tóxicas, causando redução na altura das plantas. Ramos et al. (2009), trabalhando com eucalipto citriodora, observaram que o ácido bórico aplicado acima da dose de $2,25 \mathrm{mg} \mathrm{dm}^{-3}$ provocou queda na produção de massa seca da parte aérea e raiz, indicando
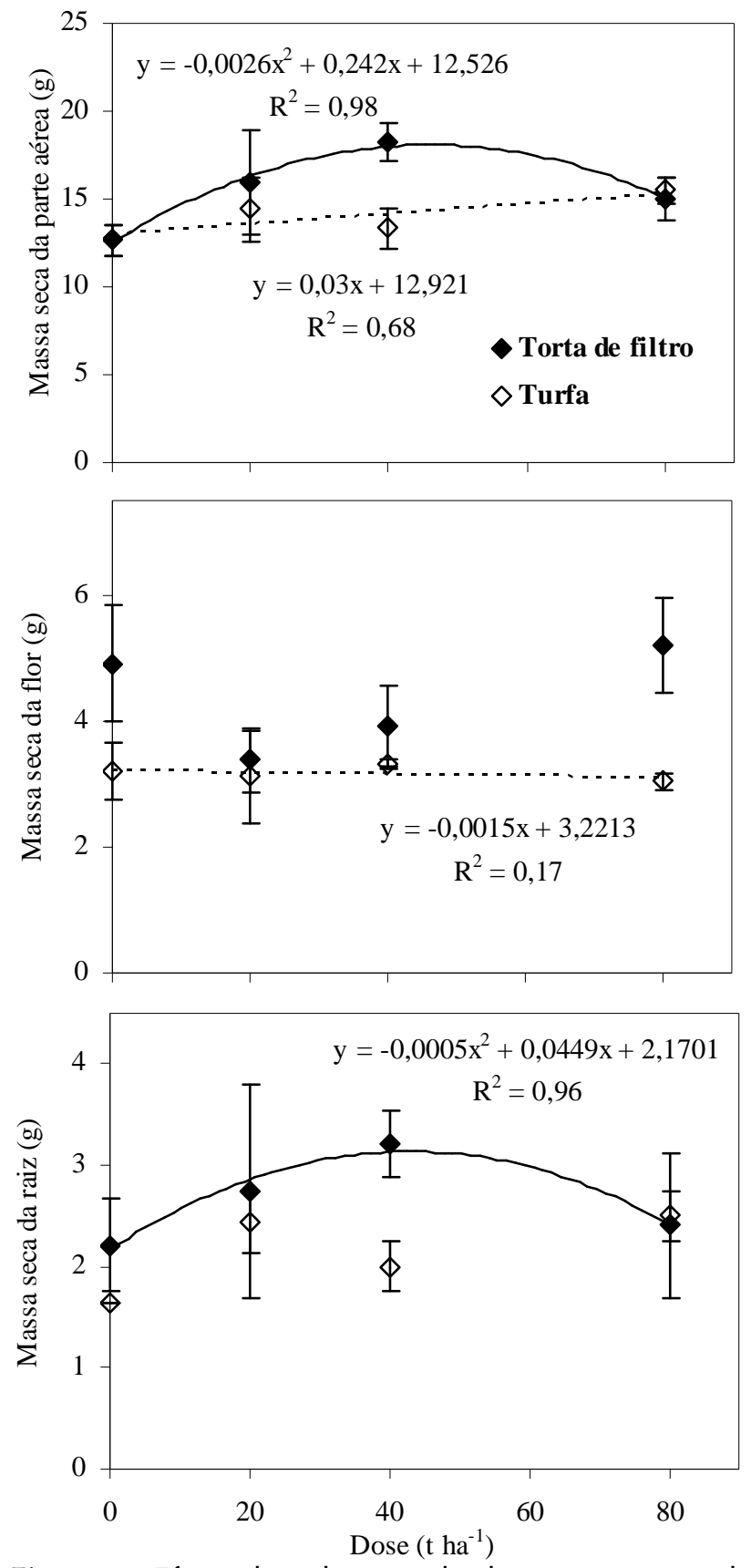

Figura 2. Efeito da aplicação de doses crescentes de torta de filtro e turfa na produção de massa seca da parte aérea, flor e raiz de plantas de girassol

toxicidade. Na dose mais elevada $6,25 \mathrm{mg} \mathrm{dm}^{-3}$ a concentração de B nas folhas novas foi de $65 \mathrm{mg} \mathrm{kg}^{-1}$ e nas velhas de $90 \mathrm{mg}$ $\mathrm{kg}^{-1}$ para plantas crescidas em LatossoloVermelho amarelo.

$\mathrm{O}$ tipo de material orgânico afetou significativamente a concentração de $\mathrm{Zn}$ em todas as partes da planta, sendo a concentração deste elemento mais elevada devido à aplicação de turfa, com efeito quadrático para raiz e parte aérea (Figura 3). O efeito das doses de MO na concentração de B foi significativo apenas para parte aérea das plantas de girassol, apresentando regressão quadrática significativa para a turfa (Figura 3). Resultado interessante foi observado na concentração de $\mathrm{Cu}$ nas raízes sendo que na presença de turfa houve um incremento linear crescente (Figura 3). Por outro 

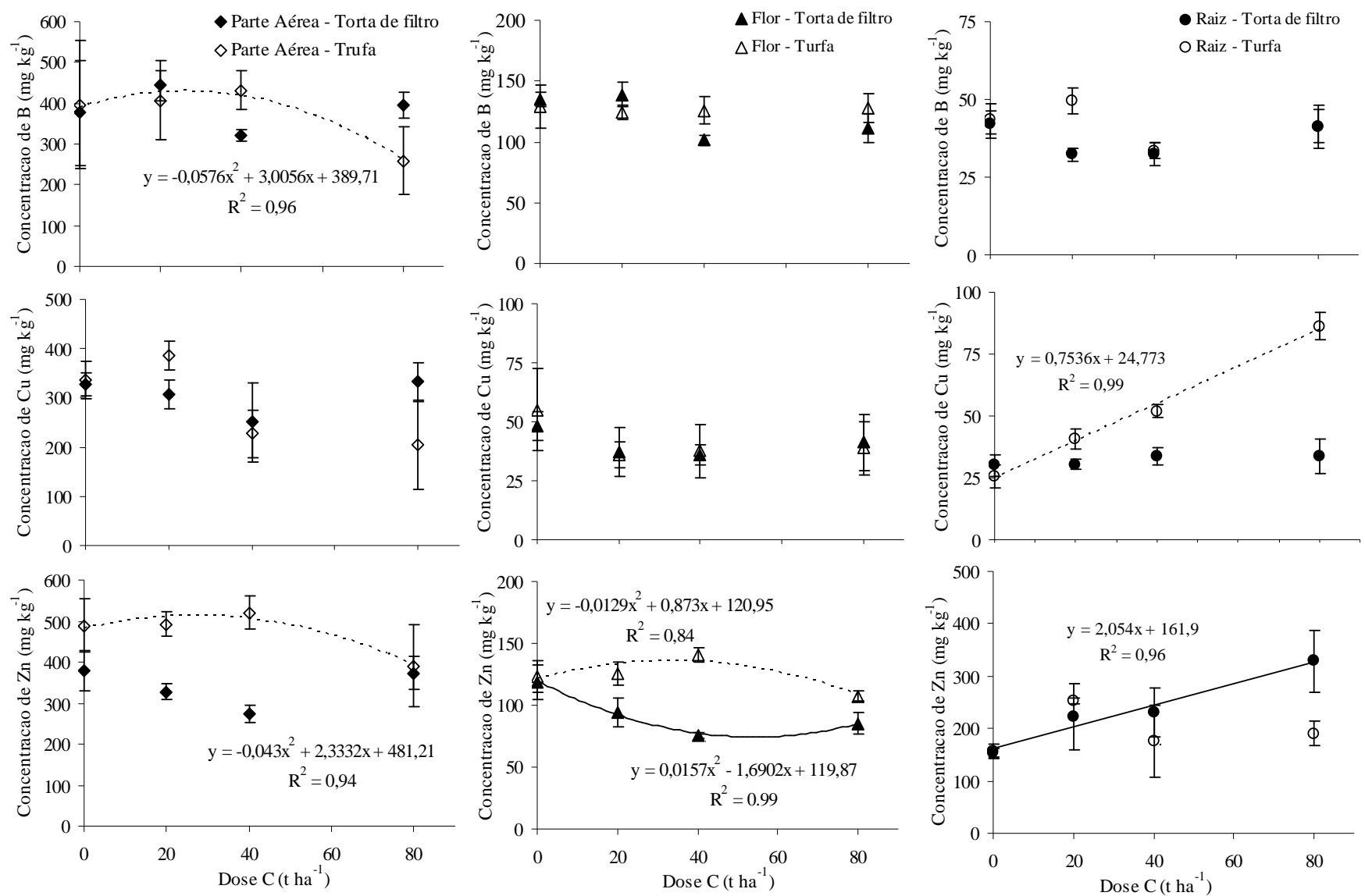

Figura 3. Concentração de boro, cobre e zinco na parte aérea, flor e raiz do girassol em função das doses de torta de filtro e de turfa aplicadas ao solo

Tabela 3. Concentração de metais pesados (cádmio, cromo, níquel e chumbo) na raiz, caule e flor do girassol, em função das doses de torta de filtro e de turfa aplicadas ao solo

\begin{tabular}{|c|c|c|c|c|c|c|c|c|c|c|c|c|c|}
\hline \multirow{3}{*}{$\begin{array}{c}\text { Fonte de C } \\
\text { org. }\end{array}$} & \multirow{3}{*}{$\begin{array}{l}\text { Dose } \\
\text { C org. } \\
\text { t ha- }^{-1}\end{array}$} & Cd & $\mathrm{Cr}$ & $\mathrm{Ni}$ & $\mathrm{Pb}$ & Cd & $\mathrm{Cr}$ & $\mathrm{Ni}$ & $\mathrm{Pb}$ & Cd & $\mathrm{Cr}$ & $\mathrm{Ni}$ & $\mathrm{Pb}$ \\
\hline & & \multicolumn{4}{|c|}{ Raiz } & \multicolumn{4}{|c|}{ Caule } & \multicolumn{4}{|c|}{ Flor } \\
\hline & & \multicolumn{12}{|c|}{$\mathrm{mg} \mathrm{kg}^{-1}$} \\
\hline \multirow{5}{*}{ Torta de filtro } & 0 & 0,1 & 12,3 & 3,9 & 18,6 & 0,1 & 0,8 & 0,1 & 0,3 & 0,1 & 0,1 & 0,1 & 0,1 \\
\hline & 20 & 0,1 & 12,7 & 5,0 & 12,2 & 0,1 & 0,7 & 0,1 & 0,9 & 0,1 & 0,1 & 0,1 & 0,1 \\
\hline & 40 & 0,1 & 11,9 & 3,5 & 14,3 & 0,1 & 0,5 & 0,1 & 0,4 & 0,1 & 0,1 & 0,1 & 0,1 \\
\hline & 80 & 0,1 & 13,2 & 6,1 & 20,0 & 0,1 & 0,7 & 0,1 & 0,9 & 0,1 & 0,1 & 0,1 & 0,1 \\
\hline & Média & 0,1 & 12,5 & 4,6 & 16,3 & 0,1 & 0,7 & 0,1 & 0,6 & 0,1 & 0,1 & 0,1 & 0,1 \\
\hline \multirow{5}{*}{ Turfa } & 0 & 0,1 & 11,9 & 4,2 & 8,1 & 0,1 & 1,0 & 0,1 & 1,0 & 0,1 & 0,1 & 0,1 & $<0,1$ \\
\hline & 20 & 0,1 & 13,2 & 5,1 & 9,5 & 0,1 & 0,9 & 0,1 & 2,0 & 0,1 & 0,1 & 0,1 & $<0,1$ \\
\hline & 40 & 0,1 & 9,1 & 4,5 & 8,2 & 0,1 & 1,0 & 0,1 & 0,6 & 0,1 & 0,1 & 0,1 & $<0,1$ \\
\hline & 80 & 0,1 & 10,2 & 4,3 & 11,3 & 0,1 & 0,5 & 0,1 & 0,5 & 0,1 & 0,1 & 0,1 & $<0,1$ \\
\hline & Média & 0,1 & 11,1 & 4,5 & 9,3 & 0,1 & 0,8 & 0,1 & 1,0 & 0,1 & 0,1 & 0,1 & $<0,1$ \\
\hline
\end{tabular}

lado, a aplicação de torta de filtro não influenciou na concentração de $\mathrm{Cu}$ nas raízes das plantas de girassol, fato passível de ser explicado pela maior complexação de Cu pela torta de filtro (Tabela 2), diminuindo sua disponibilidade para as plantas. O mesmo efeito foi observado por Santos \& Rodella (2007) em decorrência da aplicação de diferentes fontes de MO como amenizante ao solo.

As concentrações dos metais pesados $(\mathrm{Cd}, \mathrm{Cr}, \mathrm{Ni}$ e $\mathrm{Pb}) \mathrm{na}$ raiz, caule e flor do girassol, foram baixas (Tabela 3). De acordo com o Decreto $\mathrm{n}^{\circ} 55.871$, de 26 de março de 1965 (ANVISA, 2010), ainda em vigor, os limites máximos de tolerância (LMT) em alimentos (matéria seca) para os elementos $\mathrm{Cd}, \mathrm{Cr}, \mathrm{Ni}$ e $\mathrm{Pb}$ são, respectivamente, $1,0,1,0,5,0 \mathrm{e} 0,5 \mathrm{mg} \mathrm{kg}^{-1}$. Com base nessas informações conclui-se que os teores de metais pesados na flor do girassol se encontram abaixo do LMT (Tabela 3).

Embora os teores totais de $\mathrm{Cr}$ e Ni no solo estivessem entre os valores de prevenção e de intervenção agrícola, os de $\mathrm{Cd}$ entre os valores de intervenção agrícola e residencial e os de $\mathrm{Pb}$ bem próximo aos de intervenção residencial com base nos valores orientadores sugeridos pela Companhia de Tecnologia de Saneamento Ambiental (CETESB, 2010b), seus teores disponíveis, extraídos pelo DTPA pH 7,3 (Tabela 2) estavam baixos. A baixa disponibilidade dos metais pesados no solo, aliada às características das plantas de girassol, poderá impedir 
a entrada desses metais pesados na cadeia alimentar. Chaney \& Oliver (1996) afirmam que as plantas podem comportar-se como barreira importante para a transferência de contaminantes do solo para a cadeia trófica. As plantas restringem a absorção da maioria dos metais pesados do solo de forma que os seres humanos, os animais e a vida selvagem, não se encontram, de maneira geral, ameaçados pela presença desses contaminantes no solo.

\section{Índices de transferência, translocação e tempo na remoção de B e metais pesados do solo}

O índice de translocação é importante quando se trata de seleção de plantas fitorremediadoras, pois visa à retirada dos elementos do solo, desde que toda a parte aérea seja removida. Os índices aqui encontrados para B (> 99\%), $\mathrm{Cu}(>97 \%)$ e Zn (> $92 \%$ ) (Tabela 4) são considerados elevados, indicando que o B predominou na parte aérea, o que confirma sua alta mobilidade no xilema, o que é desejável para maior sucesso do processo de fitoextração. Gabos et al. (2009) encontraram valores de IT de $98 \%$ para o $\mathrm{Pb}$, em plantas de feijão-de-porco cultivadas em solo contaminado com este elemento, que recebeu aplicação de EDTA.

Tabela 4. Indice de translocação (IT), fator de transferência $(F)$, eficiência (E) dos tratamentos em remover $\mathrm{Cu}, \mathrm{Zn}$ e B do solo e o tempo (T) necessário para remediar o solo, usando-se o girassol como planta extratora

\begin{tabular}{cccc}
\hline $\begin{array}{c}\text { Fonte de C } \\
\text { org. }\end{array}$ & B & Cu & Zn \\
& \multicolumn{3}{c}{ Transferência, \% } \\
0 & 13,9 & 1,23 & 0,23 \\
Torta & 8,7 & 1,19 & 0,21 \\
Turfa & 7,9 & 0,82 & 0,24 \\
\hline \multicolumn{4}{c}{ Translocação \% } \\
0 & 99,0 & 99 & 97 \\
Torta & 99,0 & 99 & 92 \\
Turfa & 99,0 & 97 & 95 \\
\hline \multicolumn{4}{c}{ Eficiência,\% } \\
0 & 4,4 & 0,03 & 0,006 \\
Torta & 3,3 & 0,03 & 0,005 \\
Turfa & 2,5 & 0,04 & 0,006 \\
\hline \multicolumn{4}{c}{ Tempo de Remoção, anos * } \\
0 & 11,1 & - & - \\
Torta & 15,0 & - & - \\
Turfa & 25,0 & - & - \\
\hline * Consideraram-se 50\% de remoção de boro e 1 cultivo de girassol por ano
\end{tabular}

Analisando o efeito da adição de material orgânico no índice de translocação verifica-se, principalmente para o $\mathrm{Zn}$, que a aplicação de matéria orgânica ao solo influenciou de maneira negativa, ou seja, este índice foi menor (Tabela 4).

O valor do fator de transferência menor ou próximo a 1 obtido para o $\mathrm{Zn} \mathrm{e} \mathrm{Cu}$, inviabilizou o uso do girassol como planta fitoextratora para esses elementos (Tabela 4).

Analisando o efeito da adição de material orgânico no índice de transferência verifica-se, de forma principal para o $\mathrm{B}$ e $\mathrm{Cu}$, tendência negativa da aplicação de matéria orgânica, ou seja, este índice foi menor (Tabela 4). Os ligantes orgânicos, além de provocarem melhorias nas condições físicas e químicas do solo, são promissores no processo de mitigação de toxicidade de metais pesados. Santos \& Rodella (2007) observaram que a turfa e o CHM (concentrado à base de substâncias húmicas produzido a partir do carvão) atuaram como amenizantes da toxicidade de $\mathrm{Zn}, \mathrm{Cu}, \mathrm{Mn}, \mathrm{Pb}$ e $\mathrm{B}$, favorecendo o desenvolvimento da mostarda.

Para o B, o fator de transferência e o índice de translocação foram elevados, o que permitiu o cálculo do tempo de remoção, em anos, para remover $50 \%$ do teor total de boro em solo (Tabela 4). Com relação ao tempo, o uso da turfa aumentou em 14 anos e o da torta de filtro em 4 anos, ou seja, a matéria orgânica não atuou favoravelmente no processo de fitoextração (Tabela 4).

O girassol pode ser considerado planta fitoextratora somente para o B (Tabela 4). Para este elemento seriam gastos ao redor de 10 anos para reduzir em 50\% o teor de B da área de Piracicaba. Para os demais metais pesados ( $\mathrm{Zn} \mathrm{e} \mathrm{Cu}$ ), o girassol não pode ser considerado planta fitoextratora visto que o tempo de remoção de $50 \%$ dos elementos seria muito grande, inviável na prática. Resultados semelhantes obtiveram Santos \& Rodela (2007) os quais, trabalhando com a Brassica juncea (mostarda da índia), verificaram que essa planta foi eficiente apenas para extrair o B do solo e ineficiente para os elementos $\mathrm{Zn}, \mathrm{Cu}, \mathrm{Mn}$ e $\mathrm{Pb}$, em função do alto tempo de remoção necessário.

\section{ConclusõEs}

1. O girassol tem potencial para ser cultivado na área de Piracicaba, contaminada com B, Cu e Zn.

2. O girassol pode ser considerado uma fitoextratora de boro.

3. A torta de filtro e a turfa não foram eficientes como mitigadores de metais pesados e de boro.

\section{Agradecimentos}

À FAPESP, pelo financiamento do Projeto n. 2006/60987-0.

\section{LITERATURA CITADA}

Abreu, C. A.; Raij, van B.; Abreu, M. F.; González, A. P. Routine soil testing to monitor heavy metals and boron in soils. Scientia Agricola, v.62, p.1-6, 2005.

Abreu, M. F. Extração e determinação simultânea por emissão em plasma de nutrientes e elementos tóxicos em amostras de interesse agronômico. Campinas: Universidade Estadual de Campinas, 1997. 135p. Tese Doutorado

ANVISA - Agência Nacional de Vigilância Sanitária. Decreto ${ }^{\circ}$ 55.871, de 26 de março de 1965. http://www.anvisa.gov.br/ legis/decretos/55871_65.htm. 26 Mar. 2010.

Assis, R. L.; Procópio, S. O.; Carmo, M. L.; Pires, F. R.; Cargnelutti Filho, A.; Braz, G.B.P. Fitorremediação de solo contaminado com o herbicida picloram por plantas de capim pé de galinha gigante. Revista Brasileira de Engenharia Agrícola e Ambiental, v.14, p.1131-1135, 2010. 
Barros, I. T.; Andreoli, C. V.; Souza Júnior, I. G.; Costa, A. C. S. Avaliação agronômica de biossólidos tratados por diferentes métodos químicos para aplicação na cultura do milho. Revista Brasileira de Engenharia Agrícola e Ambiental, v.15, p.630-638, 2011.

Cassina, L. Tassi, E.; Morelli, E.; Giorgetti, L.; Remorini, D.; Chaney, R. L.; Barbafieri, M. Exogenous cytokinin treatments of an Ni hyper-accumulator, Alyssum Murale, grown in a serpentine soil: implications for phytoextraction. International Journal of Phytoremediation, v.13, p.90-101, 2011.

CETESB - Companhia de Tecnologia de Saneamento Ambiental. Relação de áreas contaminadas no Estado de São Paulo. http://www.cetesb.sp.gov.br. 26 Mar. 2010a.

CETESB - Companhia de Tecnologia de Saneamento Ambiental. Relatório de estabelecimento de valores orientadores para solos e águas subterrâneas para o estado de São Paulo, http://www.cetesb.sp.gov.br/Solo. 26 Mar. 2010b.

Chaney, R. L.; Oliver, D. P. Sources, potential adverse effects and remediation of agriculture soil contaminants. In: Naidu, R. (ed.). Contaminants and the soil environment in the Australasia-Pacific region. Dordrecht: Kluwer Academic Publishers, 1996. p.323-359.

Corrêa, J. C.; Büll, L. T.; Paganini, W. S.; Guerrini. I. A. Disponibilidade de metais pesados em Latossolo com aplicação superficial de escória, lama cal, lodos de esgoto e calcário, Pesquisa Agropecuária Brasileira, v.43, p.411-419, 2008.

Franchi, J. G.; Sígolo, J. B.; Lima, J. R. B. Turfa utilizada na recuperação ambiental de áreas mineradas: metodologia para avaliação laboratorial. Revista Brasileira de Geociências, v.33, p.255-262, 2003.

Gabos, M. B.; Abreu, C. A.; Coscione, A. R. EDTA assisted phytoremediation of a $\mathrm{Pb}$ contamined soil: metal leaching and uptake by jack beans. Scientia Agricola, v.66, p.506514, 2009.

Gratão, P. L.; Prasad, M. N. V.; Cardoso, P. F.; Leas, P. J.; Azevedo, R. A. Phytoremediation: Green technology for the clean up of toxic metals in the environment. Brazilian Journal of Plant Physiology, v.17, p.53-64, 2005.

Jorge, R. A. B.; Abreu, C. A.; Andrade, C. A.; Camargo, O. A. Torta de filtro e da turfa na mitigação de solo contaminado com resíduo de sucata rico em boro. Bragantia, v.1, p.1-5, 2010.

Kabata-Pendias, A. Trace elements in soil and plants. 3.ed. Boca Raton, Florida: CRC Press, 2001. 413p.

Kolbas, A.; Mench, M.; Herzig, R.; Nehnevajova, E.; Bes, C. M. Copper phytoextraction in tandem with oilseed production using commercial cultivars and mutant lines of sunflower. International Journal of Phytoremediation, v.13, p.55-76, 2011.

Kumpiene, J.; Lagerkvist, A.; Maurice, C. Stabilization of As, $\mathrm{Cr}, \mathrm{Cu}, \mathrm{Pb}$ and $\mathrm{Zn}$ in soil using amendments $-\mathrm{A}$ review. Waste Management, v.28, p.215-225, 2008.

Matos, A. T.; Carvalho, A.; Azevedo, I. C. D. d'A. Viabilidade do aproveitamento agrícola de percolados de resíduos sólidos urbanos. Revista Brasileira de Engenharia Agrícola eAmbiental, v.12, p.435-440, 2008.
Pereira, B. F. F.; Abreu, C. A.; Romeiro, S.; Paz-González, A. Pb phytoextraction by maize ina a $\mathrm{Pb}$ treated Oxisol. Scientia Agricola, v.64, p.52-60, 2007.

Ramos, S. J.; Faquin, W.; Ferreira, R. M. A.; Araújo, J. L.; Carvalho, J. G. Crescimento e teores de boro em plantas de eucalipto (Eucalyptus citriodora) cultivadas em dois latossolos sob influência de doses de boro e disponibilidade de água. Revista Árvore, v.33, p.57-65, 2009.

Ribeiro Filho, M. R.; Siqueira, J. O.; Curi, N.; Simão, J. B. P. Fracionamento e biodisponibilidade de metais pesados em solo contaminado, incubado com materiais orgânicos e inorgânicos, Revista Brasileira Ciência Solo, v.25, p.495-507, 2001.

Romeiro, S.; Lagôa, A. M. M. A.; Furlani, P. R.; Abreu, C. A.; Abreu, M. F. Lead uptake and tolerance of Ricinus communis L. Brazilian Journal of Plant Physiology, v.18, p.1-5, 2006.

Ruttens, A.; Boulet, J.; Weyens, N.; Smeets, K.; Adriaensen, K.; Meers, E.; Slycken, S. van.; Tack, F.; Meiresonne, L.; Thewys, T.; Witters, N.; Carleer, R.; Dupae, R.; Vangronsveld, J. Short rotation coppice culture of willows and poplars as energy crops on metal contaminated agricultural soils. International Journal of Phytoremediation, v.13, p.194-207, 2011.

Ruy, V. M.; Brasil Sobrinho, M. O. C.; Cabral, C. P.; Malavolta, N. L.; Malavolta, E. Contribuição para o estudo do boro disponível em solos do Estado de São Paulo. II. Nota sobre relações entre teor foliar de boro e crescimento do girassol (Helianthus annuus Mill). Revista de Agricultura, v.65, p.249255, 1990.

Santos, D. H.; Silva, M. A.; Tiritan, C. S.; Foloni, J. S. S.; Echer, F. R. Qualidade tecnológica da cana-de-açúcar sob adubação com torta de filtro enriquecida com fosfato solúvel. Revista Brasileira de Engenharia Agrícola e Ambiental, v.15, p.443449, 2011.

Santos, G. C. G.; Rodella, A. A. Efeitos da adição de fontes de matéria orgânica como amenizantes do efeito tóxico de B, $\mathrm{Zn}, \mathrm{Cu}, \mathrm{Mn}$ e $\mathrm{Pb}$ no cultivo de Brassica juncea. Revista Brasileira de Ciência do Solo, v.31, p.793-804, 2007.

Sobral, M. F.; Nascimento, C. W. A; Cunha, K. P. V.; Ferreira, H. A.; Silva, A. J.; Silva, F. B. V. Escória de siderurgia e seus efeitos nos teores de nutrientes e metais pesados em canade-açúcar. Revista Brasileira de Engenharia Agrícola e Ambiental, v.15, p.867-872, 2011.

USEPA - United States Environmental Protection Agency. Method 3051: microwave assisted acid digestion of sediments, sludges, soil and soils. http://www.epa.gov/ epaoswer/hazwaste/test/3_series.htm. 10 Jan. 2007.

van Raij, B.; Andrade, J. C.; Cantarella, H.; Quaggio, J. A(ed.). Análise química para avaliação da fertilidade de solos tropicais. Campinas: Instituto Agronômico, 2001. p.189-199. van Raij, B.; Camargo, C. E. O. Cereais. In: Raij, B. van; Cantarella, H.; Quaggio, J. A.; Furlani, A. M. C. (ed.). Recomendações de adubação e calagem para o Estado de São Paulo. Campinas: Instituto Agronômico, 1997. p.45-47. Boletim Técnico, 100.

Zeitouni, C. F.; Berton, R. S.; Abreu, C. A fitoextração de cádmio e zinco de um latossolo vermelho-amarelo contaminado com metais pesados. Bragantia, v.66, p.649-657, 2007. 